\title{
FULFIL Trial: Once-Daily Triple Therapy in Patients with Chronic Obstructive Pulmonary Disease
}

David A. Lipson ${ }^{1,2}$, Helen Barnacle ${ }^{3}$, Ruby Birk ${ }^{3}$, Noushin Brealey ${ }^{3}$, Nicholas Locantore $^{1}$, David A. Lomas ${ }^{4}$, Andrea Ludwig-Sengpiel ${ }^{5}$, Rajat Mohindra ${ }^{3^{*}}$, Maggie Tabberer $^{3}$, Chang-Qing Zhu ${ }^{3}$, and Steven J. Pascoe ${ }^{1}$

${ }^{1}$ GSK, King of Prussia, Pennsylvania; ${ }^{2}$ Perelman School of Medicine, University of Pennsylvania, Philadelphia, Pennsylvania; ${ }^{3}$ GSK, Stockley Park West, Uxbridge, Middlesex, United Kingdom; ${ }^{4}$ UCL Respiratory, University College London, London, United Kingdom; and ${ }^{5}$ KLB Health Research, Lübeck, Germany

* Employee of GSK at the time of study. Current affiliation is Roche, Basel, Switzerland.

\section{Corresponding Author:}

David A. Lipson, MD

GSK, 709 Swedeland Road, UW2531, King of Prussia, PA 19406

E-mail: david.a.lipson@gsk.com

Tel: (+1) 610-270-7166

Fax: (+1) 610-270-5360

\section{Author Contributions:}

Literature search: DALp, NB, HB

Study design: DALp, NL, MT, NB, HB, RM

Data collection: DALp, NL, CQZ, MT, NB, HB, AL-S, RM 
Data analysis: DALp, NL, DALm; CQZ, NB, RM

Data interpretation: all authors

Writing/reviewing of the manuscript: all authors

Final approval of the manuscript: all authors

Funding: This study was funded by GSK (ClinicalTrials.gov number NCT02345161;

GSK study CTT116853)

Running Title: Closed triple therapy for COPD: FULFIL results

Subject Category: 9.14 COPD: Pharmacological Treatment

Total Word Count: 3196

\section{At a Glance Commentary:}

Although inhaled triple pharmacologic therapy is recommended for patients with advanced chronic obstructive pulmonary disease and is often used clinically as stepup treatment, few randomized controlled trials have assessed the benefit of triple therapy compared with dual inhaled corticosteroid/long-acting $\beta_{2}$-agonist therapy. Results from the FULFIL study demonstrated the clinical benefit of once-daily fluticasone furoate/umeclidinium/vilanterol (FF/UMEC/VI) combination therapy using a single inhaler compared with twice-daily budesonide/formoterol (BUD/FOR) combination therapy. Once-daily FF/UMEC/VI improved lung function and healthrelated quality of life, as well as reducing exacerbation frequency, compared with twice-daily BUD/FOR.

Online Data Supplement: This article has an online data supplement, which is accessible from this issue's table of content online at www.atsjournals.org. 


\section{Abstract}

Rationale: Randomized data comparing triple therapy with dual inhaled corticosteroid (ICS)/long-acting $\beta_{2}$-agonist (LABA) therapy in patients with chronic obstructive pulmonary disease (COPD) are limited.

Objectives: We compared the effects of once-daily triple therapy on lung function and health-related quality of life with twice-daily ICS/LABA therapy.

Methods: FULFIL was a randomized, double-blind, double-dummy study comparing 24 weeks of once-daily triple therapy (fluticasone furoate/umeclidinium/vilanterol $100 \mu \mathrm{g} / 62.5 \mu \mathrm{g} / 25 \mu \mathrm{g}$; ELLIPTA ${ }^{\circledR}$ inhaler) with twice-daily ICS/LABA therapy (budesonide/formoterol $400 \mu \mathrm{g} / 12 \mu \mathrm{g}$; Turbuhaler $^{\circledR}$ ). A patient subgroup remained on blinded treatment for up to 52 weeks. Co-primary endpoints were change from baseline in trough forced expiratory volume in 1 second $\left(\mathrm{FEV}_{1}\right)$ and in St George's Respiratory Questionnaire (SGRQ) Total score, at Week 24.

Measurements and Main Results: In the intent-to-treat population $(N=1,810)$ at Week 24 for triple therapy $(n=911)$ and ICS/LABA therapy $(n=899)$ : mean change from baseline in FEV 1 was $142 \mathrm{~mL}(95 \%$ confidence interval [Cl], 126,158) and -29 $\mathrm{mL}(95 \% \mathrm{Cl},-46,-13)$, respectively; mean change from baseline SGRQ was -6.6 units $(95 \% \mathrm{Cl},-7.4,-5.7)$ and -4.3 units $(95 \% \mathrm{Cl},-5.2,-3.4)$, respectively. For both endpoints, the between-group differences were statistically significant $(P<0.001)$. There was a statistically significant reduction in moderate/severe exacerbation rate with triple versus ICS/LABA therapy $(35 \%$ reduction, $95 \% \mathrm{CI}, 14,51 ; P=0.002)$. The safety profile of triple therapy reflected the known profiles of the components.

Conclusions: These results support the benefits of single inhaler triple therapy compared with ICS/LABA therapy, in patients with advanced COPD. 
Abstract word count: 246

Keywords: COPD; single inhaler triple therapy; lung function; health-related quality of life 


\section{Introduction}

The use of inhaled triple pharmacologic therapy by patients with chronic obstructive pulmonary disease (COPD) is common; a UK study found that after 2 years, $46 \%$ of patients initially prescribed a long-acting bronchodilator and $39 \%$ of those prescribed an inhaled corticosteroid (ICS)/long-acting $\beta_{2}$-agonist (LABA) or ICS plus long-acting muscarinic antagonist (LAMA) progressed to triple therapy (1). In a US study, $25.5 \%$ of patients with COPD, who had received at least one LAMA, LABA, ICS, or phosphodiesterase-4 inhibitor, received triple therapy within 2 years of being diagnosed (2). The Global Initiative for Chronic Obstructive Lung Disease strategy document recommends inhaled triple pharmacologic therapy (ICS/LAMA/LABA) for patients with advanced COPD with persistent symptoms and risk of exacerbations (3).

Despite the current widespread use of triple therapy, there are few randomized controlled trials demonstrating a sustained benefit on lung function and patient reported outcome measures compared with ICS/LABA alone (4). Recently, a oncedaily single inhaler triple therapy of fluticasone furoate/umeclidinium/vilanterol (FF/UMEC/VI) $100 \mu \mathrm{g} / 62.5 \mu \mathrm{g} / 25 \mu \mathrm{g}$ has been developed for patients with moderate to very severe COPD. This 'closed triple' therapy may offer clinically important improvements in lung function and quality of life compared with ICS/LABA dual therapy, as well as eliminating the need for delivering the medications using multiple inhalers. Single inhaler triple therapy may reduce the risk of medication errors and may help to ensure that a patient receives all three medications.

FULFIL (Lung FUnction and quality of LiFe assessment in COPD with closed trlpLe therapy) is the first study to compare once-daily single inhaler triple therapy (ICS/LABA/LAMA) with twice-daily dual therapy (ICS/LABA) in patients with 
advanced, symptomatic COPD, who are at risk of exacerbations. It was designed in part to support the registration of once-daily FF/UMEC/VI in Europe and other countries globally. In consultation with European regulators, the sponsor was asked to provide a comparison with an ICS/LABA dual combination product indicated to treat patients with COPD, which was well known and well understood by physicians. BUD/FOR was chosen as it is a commonly prescribed medication for patients with COPD. The study provides comparative information not just between classes of therapies but also between different molecules with different dosing regimens.

FULFIL was specifically designed to have a close resemblance to real-world clinical practice. It compared a once-daily triple pharmacologic therapy to a current standard-of-care ICS/LABA, and the run-in period allowed patients to continue on their pre-study maintenance therapy up to randomization to mimic switch scenarios in clinical practice. FULFIL also allowed inclusion of patients with commonly observed comorbidities who are often excluded from other trials. The patient's perspective was carefully evaluated using a health-related quality of life co-primary endpoint. Some of the results have been previously reported in the form of an abstract (5).

\section{Methods}

\section{Trial Design and Oversight}

FULFIL was a phase III, randomized, double-blind, double-dummy, parallel-group, multicenter study (ClinicalTrials.gov number, NCT02345161; GSK study CTT116853). Patients were randomized to receive 24 weeks of once-daily 
FF/UMEC/VI $(100 \mu \mathrm{g} / 62.5 \mu \mathrm{g} / 25 \mu \mathrm{g})$ using a single ELLIPTA ${ }^{\circledR}$ inhaler and twice-daily placebo using the Turbuhaler $^{\circledR}$, or twice-daily budesonide/formoterol (BUD/FOR) $(400 \mu \mathrm{g} / 12 \mu \mathrm{g})$ using the Turbuhaler ${ }^{\circledR}$ and once-daily placebo using the ELLIPTA ${ }^{\circledR}$ inhaler. Twice-daily BUD/FOR using the Turbuhaler ${ }^{\circledR}$ was the comparator, as this ICS/LABA is commonly used in this patient population. All patients took one inhalation from the ELLIPTA ${ }^{\circledR}$ inhaler in the morning and two inhalations (one in the morning and one in the evening) from the Turbuhaler ${ }^{\circledR}$ to minimize the impact of different dosing regimens.

There was a 2-week run-in period, during which medications at screening were unchanged, followed by a 24-week treatment period. A subset of the first 430 patients to enroll in the trial and consent to longer-term treatment remained on blinded study treatment for up to 52 weeks. To minimize loss of data, patients who permanently discontinued study treatment (but did not withdraw consent) were not required to withdraw from the study, but could continue to have certain safety and efficacy assessments conducted.

The primary objectives were to evaluate the effects of once-daily single inhaler triple therapy (FF/UMEC/NI) on lung function and health-related quality of life compared with twice-daily dual ICS/LABA therapy (BUD/FOR) at 24 weeks.

The institutional review boards for human studies approved the protocol and written consent was obtained from the subjects or their surrogates as required by the institutional review boards.

\section{Study Endpoints}

The co-primary endpoints were change from baseline in trough forced expiratory volume in 1 second $\left(\mathrm{FEV}_{1}\right)$ and change from baseline in St George's Respiratory 
Questionnaire (SGRQ) Total score, at Week 24. Supportive analyses for the primary endpoints included: proportion of patients with a clinically meaningful change from baseline in trough $\mathrm{FEV}_{1}(\geq 100 \mathrm{~mL})$ and change from baseline SGRQ Total score ( $\geq 4$ unit decrease); change from baseline in Evaluating Respiratory Symptoms in COPD score (E-RS: COPD; formerly EXACT RS) over 24 weeks and the proportion of responders. Population pharmacokinetic analyses were conducted on serial and sparse blood samples collected from a subset of patients $(n=74)$ to assess FF, UMEC, and VI systemic exposure from a single inhaler.

Efficacy and safety endpoints were analyzed up to Week 24 in the intent-totreat (ITT) population and up to Week 52 in the extension (EXT) population.

\section{Patients}

FULFIL enrolled patients with COPD aged $\geq 40$ years defined as Global Initiative for Chronic Obstructive Lung Disease Group D: $\mathrm{FEV}_{1}<50 \%$ and COPD Assessment is Test $^{\mathrm{TM}} \geq 10$, or patients with $\mathrm{FEV}_{1} \geq 50-<80 \%$ and COPD Assessment Test $^{\mathrm{TM}} \geq 10$, and either $\geq 2$ moderate exacerbations in the past year or $\geq 1$ severe exacerbation in the past year. Patients were required to be receiving daily maintenance therapy for COPD for $\geq 3$ months. Patients were excluded if they had a current diagnosis of asthma causing their symptoms, or unresolved pneumonia or severe COPD exacerbation. Demographic and disease characteristics were recorded at screening.

\section{Efficacy Assessments}

Spirometry was performed in all patients at baseline and at Weeks 2, 4, 12, 24, and at Weeks 36 and 52 in the EXT population, using standardized equipment according to the American Thoracic Society-European Respiratory Society criteria (6). The 
SGRQ for COPD patients was completed using a patient-held eDiary at Day 1 and at Weeks 4 and 24 (and Week 52 for the EXT population). Potential COPD exacerbations were identified based on symptoms reported using the eDiary, which triggered follow-up with the investigator, who confirmed any exacerbations based on an interaction with the patient. Mild exacerbations were defined as worsening symptoms of COPD that were self-managed by the patient (e.g. increase in albuterol use) and not associated with the use of corticosteroids or antibiotics. A moderate exacerbation was defined as having worsening symptoms of COPD that required treatment with oral/systemic corticosteroids and/or antibiotics. A severe exacerbation was defined as worsening symptoms of COPD that required treatment with in-patient hospitalization. The E-RS: COPD questionnaire was completed each evening using the eDiary.

\section{Safety Assessments}

The incidence of adverse events (AEs), serious AEs (SAEs), pneumonia and supporting radiography, cardiovascular events including pre-specified major cardiovascular events analysis, bone fractures, and other AEs of special interest (AESI) were evaluated in the study (AESI are listed in Table E1 in the online data supplement).

\section{Statistical Analyses}

Statistical analyses were carried out using SAS Version 9.3. Sample size was calculated based on the co-primary endpoints and previous experience with drugs of these classes. The ITT population, stratified by smoking status, comprised all randomized patients, excluding those who were randomized in error who did not 
receive a dose of study medication. The EXT population comprised the subset of patients in the ITT population who were enrolled into the 52-week extension phase. The co-primary endpoints were analyzed using mixed model repeated measures and were adjusted for multiplicity using the Hochberg method.

Further details of the methods are provided in the online data supplement.

\section{Results}

\section{Patients}

In total, 1,810 patients were included in the ITT population (FF/UMEC/VI, $\mathrm{n}=911$;

BUD/FOR, $n=899)$ and 430 in the EXT population (FF/UMEC/VI, $n=210$;

BUD/FOR, $n=220$ ) (Figure E1 in the online data supplement). Overall, $94 \%$ of patients completed the study and $90 \%$ completed the study on investigational treatment; premature treatment discontinuations were most frequently due to patient decision (4\%), AE, or lack of efficacy (both $3 \%$ ). Patient and disease characteristics at baseline for the ITT and EXT populations are shown in Table 1. COPD medications used during the study run-in are provided in Table E2 in the online data supplement.

\section{Co-Primary Endpoints}

In the ITT population, FF/UMEC/VI demonstrated clinically meaningful improvements from baseline in trough $\mathrm{FEV}_{1}$ at all time points over the 24-week treatment period (Figure 1A; Table 2). At Week 24, the mean change from baseline in trough FEV 1 was $142 \mathrm{~mL}(95 \%$ confidence interval [CI], 126,158) for FF/UMEC/VI and -29 mL 
$(95 \% \mathrm{Cl},-46,-13)$ for BUD/FOR; the difference between FF/UMEC/VI and BUD/FOR was statistically significant $(171 \mathrm{~mL} ; 95 \% \mathrm{Cl}, 148,194 ; P<0.001)$ (Table 2$)$. The treatment differences ranged from 123 to $171 \mathrm{~mL}$ and were statistically significant in favor of FF/UMEC/VI at all time points $(P<0.001)$.

In the ITT population, at Week 24, clinically meaningful improvements in SGRQ Total score were observed in both treatment groups. The change from baseline in SGRQ was -6.6 units $(95 \% \mathrm{Cl},-7.4,-5.7)$ with $\mathrm{FF} / \mathrm{UMEC} / \mathrm{VI}$ and $-4.3(95 \% \mathrm{Cl},-5.2,-$ 3.4) with BUD/FOR. The between-treatment difference in improvement in SGRQ Total score was statistically significant for FF/UMEC/VI (-2.2 units; 95\% Cl, -3.5,-1.0; $P<0.001$ ) compared with BUD/FOR (Table 2).

Similar findings in change from baseline in trough $\mathrm{FEV}_{1}$ were observed in the EXT population at Week 52 (Figure 1B; Table 2). The mean change from baseline in trough $\mathrm{FEV}_{1}$ was $126 \mathrm{~mL}(95 \% \mathrm{Cl}, 92,159)$ for FF/UMEC/VI and $-53 \mathrm{~mL}(95 \% \mathrm{Cl}$, $87,-20)$ for BUD/FOR. The mean change from baseline in SGRQ Total score in the EXT population was -4.6 units $(95 \% \mathrm{CI},-6.5,-2.6)$ with $\mathrm{FF} / \mathrm{UMEC} / \mathrm{VI}$ and -1.9 units $(95 \% \mathrm{Cl},-3.9,0.1)$ with BUD/FOR, and although the between-treatment difference was of a similar magnitude to that observed in the ITT population, it did not reach statistical significance (Table 2).

\section{Selected Secondary and Other Endpoints}

In the ITT population at Week 24 , an increase of $\geq 100 \mathrm{~mL}$ from baseline in trough $\mathrm{FEV}_{1}$ was achieved by a larger proportion of patients in the FF/UMEC/VI group (453; $50 \%$ ) than in the BUD/FOR group (184; $21 \%$ ). The odds ratio (OR) of achieving versus not achieving this increase was statistically significant in favor of FF/UMEC/VI (OR, 4.03; 95\% Cl, 3.27,4.97; $P<0.001)$. 
A larger proportion of patients in the FF/UMEC/VI group (448; $50 \%)$ than in the BUD/FOR group (368; 41\%) experienced a clinically meaningful improvement from baseline ( $\geq 4$ unit decrease) in SGRQ Total score in the ITT population at Week 24. The OR of response versus non-response was statistically significant in favor of FF/UMEC/VI (OR, 1.41; 95\% Cl, 1.16,1.70; $P<0.001)$ (Table 2).

The incidence of moderate/severe COPD exacerbations over the 24-week treatment period was $10 \%(n=95)$ and $14 \%(n=126)$ for $F F / U M E C / V I$ and BUD/FOR, respectively. The mean annualized rate of moderate/severe exacerbations was 0.22 and 0.34 for FF/UMEC/VI and BUD/FOR, respectively, and the reduction in the annualized rate was statistically significant $(35 \% ; 95 \% \mathrm{Cl}$, $14,51 \% ; P=0.002$ ) based on data up to 24 weeks in the ITT population (Table 3). Similar statistically significant results were observed for mild/moderate/severe exacerbations (Table 3). Fewer patients were hospitalized for exacerbations in the FF/UMEC/VI treatment group (12 [1\%]) than in the BUD/FOR group (22 [2\%]).

For the ITT population, at each 4-week interval over the 24-week treatment period, FF/UMEC/VI produced greater reductions from baseline in E-RS: COPD total score compared with BUD/FOR and the treatment differences were statistically significant $(P<0.001)$ (Figure 2). The ORs for response versus non-response for each 4-week interval were statistically significant in favor of FF/UMEC/VI (OR ranging 1.59,1.76; $P<0.001)$. Similar results were observed for each E-RS: COPD subscale (breathlessness; cough and sputum; chest symptoms).

The results for the secondary and other endpoints described here were also observed up to 52 weeks in the EXT population (see respective tables and figures). 


\section{Safety Analyses}

The incidence of on-treatment AEs in the ITT population up to Week 24 was $38.9 \%$ in the FF/UMEC/VI group and $37.7 \%$ in the BUD/FOR group; the most common AEs were nasopharyngitis ( $7 \%$ and $5 \%$ for FF/UMEC/VI and BUD/FOR, respectively) and headache (5\% and $6 \%$ for FF/UMEC/VI and BUD/FOR, respectively) (Table 4). A similar pattern was observed in the EXT population up to Week 52; the most common AEs were nasopharyngitis (11\% and $10 \%$ for FF/UMEC/VI and BUD/FOR, respectively) and headache ( $8 \%$ and $10 \%$ for FF/UMEC/VI and BUD/FOR, respectively). COPD worsening was one of the most common AEs in the BUD/FOR group (10\%), but was less common in the FF/UMEC/VI group (2\%) in the EXT population up to Week 52 .

For FF/UMEC/VI and BUD/FOR, respectively: the incidence of on-treatment SAEs in the ITT population up to Week 24 was $5.4 \%$ and $5.7 \%$; the most common on-treatment SAEs were COPD exacerbation (1.3\% and $2.3 \%)$ and pneumonia $(1.0 \%$ and $0.3 \%)$. There were 12 on-treatment deaths in this study (six in each treatment group), which was in line with expectations for patients with advanced COPD and multiple comorbidities. The incidence of adjudicated on-treatment nonfatal SAEs in the ITT population was $4.9 \%$ in the FF/UMEC/VI group and $5.2 \%$ in the BUD/FOR group. Of these (for FF/UMEC/VI and BUD/FOR, respectively), COPD exacerbations (1.5\% and $2.4 \%$ ) and pneumonia and/or respiratory tract infection without COPD exacerbation $(0.9 \%$ and $0.3 \%)$ were the most common. An overview of the rate of drug-related AEs and SAEs is provided in the Results section of the online data supplement.

The incidence of pre-specified AESIs in the ITT population was also investigated. For FF/UMEC/VI and BUD/FOR, respectively: cardiovascular effects 
were reported by $4.3 \%$ and $5.2 \%$ of patients and the incidence of pneumonia was $2.2 \%$ and $0.8 \%$ in the ITT population up to Week 24 (Table 4 ).

The incidence of on-treatment SAEs in the EXT population was $10.0 \%$ in the FF/UMEC/VI group and $12.7 \%$ in the BUD/FOR group. In the EXT population up to Week 52, for FF/UMEC/VI and BUD/FOR, respectively, cardiovascular effects as AESI were reported by $8.6 \%$ and $10.0 \%$ of patients, and the incidence of pneumonia as an AESI was $1.9 \%$ and $1.8 \%$ (Table 4$)$.

The incidence of major cardiovascular events was $0.4 \%$ and $0.8 \%$ in the ITT population up to Week 24 , and $2.4 \%$ and $0.9 \%$ in the EXT population up to Week 52 , for FF/UMEC/VI and BUD/FOR, respectively. There were no clinically significant differences between treatment groups in vital signs, electrocardiograms, Holter findings, or laboratory values.

Population pharmacokinetic analyses showed that systemic drug levels of FF, UMEC, and $\mathrm{VI}$ following FF/UMEC/VI administration using a single inhaler (triple therapy) were low and within the range observed following dual therapy (FF/VI and UMEC/VI) and monotherapy (FF, UMEC, and VI) $(7,8)$.

\section{Discussion}

Our results show that once-daily FF/UMEC/VI offered clinically meaningful and statistically significant improvements at Week 24 in lung function and health-related quality of life compared with BUD/FOR. The improvements in health-related quality of life were reflected in the consistent reduction in total symptoms, measured using the E-RS: COPD. At each 4-weekly time point, FF/UMEC/VI demonstrated greater symptom reduction than BUD/FOR. Clinically meaningful and statistically significant reductions in exacerbation rates for patients with COPD were also observed with 
FF/UMEC/VI compared with BUD/FOR, at Week 24. Importantly, the benefits of FF/UMEC/VI on lung function, health-related quality of life, and exacerbation rate were sustained over 52 weeks in the EXT population. The magnitude of the between-treatment difference in SGRQ Total score between treatment groups at Week 52 failed to achieve statistical significance, possibly due to the smaller size of this subgroup. The lung function findings reported here are in keeping with the results of shorter studies of triple therapy using FF/VI and UMEC in two separate inhalers $(4,9)$.

The safety profile of FF/UMEC/VI, including the systemic exposure, was in line with the known profiles of the component drugs, and findings from the 52-week EXT population suggest that there are no cumulative adverse effects from once-daily FF/UMEC/VI. While the incidence of pneumonia was higher with FF/UMEC/VI than with BUD/FOR in the ITT population up to 24 weeks, it was similar between the two groups in the smaller EXT population at 52 weeks. The incidence of pneumonia with FF/UMEC/VI observed here is consistent with reports from other 24-week studies of FF/VI for COPD, which reported incidences of up to $2 \%(10,11)$, and studies of BUD/FOR for COPD $(12,13)$. The incidence of pneumonia is also similar to that observed in another study of ICS/LABA/LAMA therapy for COPD, in which pneumonia occurred in $3 \%$ of patients in both the triple therapy and the ICS/LABA comparator arms (14) and is less than the incidence reported in 52-week studies of FF/VI (15) and BUD/FOR (16). No excess risk of pneumonia with FF or VI either alone or in combination, compared with placebo, was found in the SUMMIT study (although SUMMIT included patients with moderate airflow limitation and only 39\% had a history of exacerbations) (17).

Although this study was focused on non-exacerbation outcomes and the 
proportion of patients with exacerbations in the overall population was low, there were clear efficacy benefits in favor of FF/UMEC/VI on these outcome measures in both the ITT and EXT populations.

FULFIL was designed to be as inclusive as possible, allowing patients with COPD who also had significant cardiovascular disease to be enrolled. Furthermore, patients remained on their usual standard medications during the run-in and were not artificially required to withdraw medications. This meant the study population may more closely reflect the real-world population of patients with COPD and increases the generalizability of the study findings. FULFIL was also designed to minimize data loss, by enabling data collection to continue following treatment discontinuation. All SAE reports were independently adjudicated, and a chest radiograph was required for all patients with suspected pneumonia or a moderate/severe exacerbation, which improved the characterization of safety findings.

This study compared an ICS/LABA/LAMA (FF/UMEC/VI) combination with an ICS/LABA (BUD/FOR) using different dosing regimens (once daily vs. twice daily) in different inhalers. The double-dummy study design aimed to mitigate some of these differences, so the results reported are a direct comparison of the products rather than the addition of a LAMA to ICS/LABA. However, there is evidence supporting the value of incremental LAMA therapy $(4,9,14,18)$. Two randomized, 3-month studies showed clinically relevant improvements in lung function with UMEC plus FF/VI, compared with placebo plus FF/VI, in patients with moderate-to-very severe COPD (9). The TRILOGY study (14) showed that triple therapy compared with ICS/LABA had a modest benefit with a reduction in exacerbations and an improvement in health-related quality of life; however, this appeared to wane as the study continued. A post-hoc analysis of four trials that assessed UMEC or placebo plus ICS/LABA 
(including the two studies described previously) showed that triple therapy improved lung function and health-related quality of life, and reduced the risk of exacerbations compared with ICS/LABA (4). Of note, in FULFIL, the benefits of FF/UMEC/VI over BUD/FOR seem substantially greater and more persistent than those seen in the comparison of beclomethasone dipropionate/formoterol/glycopyrronium bromide with beclomethasone dipropionate/formoterol (14). This could be due to the advantages of once-daily versus twice-daily dosing, the differences in the individual components, or a combination of the two. Further study is needed to clarify the drivers of these differences.

Results from the FULFIL study demonstrated the clinical value of triple therapy using FF/UMEC/VI, compared with dual BUD/FOR therapy, for symptomatic patients with advanced COPD who are at risk of exacerbations. Once-daily single inhaler triple therapy provides a straightforward dosing option for patients with COPD and this reduction in polypharmacy using multiple inhalers may reduce the likelihood of inhaler use errors, although all inhaler types may be associated with errors in use (19-21). Single inhaler triple therapy offers clinically important benefits in lung function, health-related quality of life, and reduction in risk of exacerbation, which were also observed over 52 weeks. 


\section{Acknowledgments}

We would like to thank the patients and their families for participating in this study, Eva Gomez (GSK, Operations Lead), Niki Day (GSK Clinical Safety Scientist), Erik Steinberg (GSK Data Quality Leader), and the FULFIL study team. We would also like to thank Veramed for support with statistical analyses.

Medical writing support in the form of development of the draft outline and manuscript drafts in consultation with the authors, editorial suggestions to draft versions of this paper, assembling tables and figures, collating author comments, copyediting, referencing and graphic services was provided by Alison Scott, PhD of Gardiner-Caldwell Communications, Macclesfield, UK and was funded by GSK. 


\section{References}

1. Wurst KE, Punekar YS, Shukla A. Treatment evolution after COPD diagnosis in the UK primary care setting. PLoS One 2014;9:e105296.

2. Simeone JC, Luthra R, Kaila S, Pan X, Bhagnani TD, Liu J, Wilcox TK. Initiation of triple therapy maintenance treatment among patients with COPD in the US. Int J Chron Obstruct Pulmon Dis 2017;12:73-83.

3. Global Initiative for Chronic Obstructive Lung Disease (GOLD). GOLD 2017 global strategy for the diagnosis, management and prevention of COPD. 2017 [cited 2016 Dec 11]. Available from: http://goldcopd.org/gold-2017-globalstrategy-diagnosis-management-prevention-copd/

4. Siler TM, Kerwin E, Tombs L, Fahy WA, Naya I. Triple therapy of umeclidinium + inhaled corticosteroids/long-acting beta 2 agonists for patients with COPD: pooled results of randomized placebo-controlled trials. Pulm Ther 2016;2:43-58. Available from: http://rd.springer.com/article/10.1007/s41030-016-0012-4

5. Lomas D, Lipson D, Barnacle H, Birk R, Brealey N, Zhu C-Q, Tabberer M. Single inhaler triple therapy (ICS/LAMA/LABA) in patients with advanced COPD: results of the FULFIL trial. Eur Respir J 2016;48:PA4629.

6. Miller MR, Hankinson J, Brusasco V, Burgos F, Casaburi R, Coates A, Crapo R, Enright P, van der Grinten CP, Gustafsson P, Jensen R, Johnson DC, Maclntyre N, McKay R, Navajas D, Pedersen OF, Pellegrino R, Viegi G, Wanger J; ATS/ERS Task Force. Standardisation of spirometry. Eur Respir J 2005;26:319338.

7. Goyal N, Beerahee M, Kalberg C, Church A, Kilbride S, Mehta R. Population pharmacokinetics of inhaled umeclidinium and vilanterol in patients with chronic obstructive pulmonary disease. Clin Pharmacokinet 2014;53:637-648. 
8. Siederer S, Allen A, Yang S. Population pharmacokinetics of inhaled fluticasone furoate and vilanterol in subjects with chronic obstructive pulmonary disease. Eur J Drug Metab Pharmacokinet 2015;41:743-758.

9. Siler TM, Kerwin E, Sousa AR, Donald A, Ali R, Church A. Efficacy and safety of umeclidinium added to fluticasone furoate/vilanterol in chronic obstructive pulmonary disease: results of two randomized studies. Respir Med 2015;109:1155-1163.

10. Martinez FJ, Boscia J, Feldman G, Scott-Wilson C, Kilbride S, Fabbri L, Crim C, Calverley PM. Fluticasone furoate/vilanterol (100/25; 200/25 $\mu \mathrm{g})$ improves lung function in COPD: a randomised trial. Respir Med 2013;107:550-559.

11. Kerwin EM, Scott-Wilson C, Sanford L, Rennard S, Agusti A, Barnes N, Crim C. A randomised trial of fluticasone furoate/vilanterol $(50 / 25 \mu \mathrm{g} ; 100 / 25 \mu \mathrm{g})$ on lung function in COPD. Respir Med 2013;107:560-569.

12. Rennard SI, Tashkin DP, McElhattan J, Goldman M, Ramachandran S, Martin UJ, Silkoff PE. Efficacy and tolerability of budesonide/formoterol in one hydrofluoroalkane pressurized metered-dose inhaler in patients with chronic obstructive pulmonary disease: results from a 1-year randomized controlled clinical trial. Drugs 2009;69:549-565.

13. Tashkin DP, Rennard SI, Martin P, Ramachandran S, Martin UJ, Silkoff PE, Goldman M. Efficacy and safety of budesonide and formoterol in one pressurized metered-dose inhaler in patients with moderate to very severe chronic obstructive pulmonary disease. Drugs 2008;68:1975-2000.

14. Singh D, Papi A, Corradi M, Pavlišová I, Montagna I, Francisco C, Cohuet G, Vezzoli S, Scuri M, Vestbo J. Single inhaler triple therapy versus inhaled corticosteroid plus long-acting $\beta 2$-agonist therapy for chronic obstructive 
pulmonary disease (TRILOGY): a double-blind, parallel group, randomised controlled trial. Lancet 2016;388:963-973.

15. Dransfield MT, Bourbeau J, Jones PW, Hanania NA, Mahler DA, Vestbo J, Wachtel A, Martinez FJ, Barnhart F, Sanford L, Lettis S, Crim C, Calverley PM. Once-daily inhaled fluticasone furoate and vilanterol versus vilanterol only for prevention of exacerbations of COPD: two replicate double-blind, parallel-group, randomised controlled trials. Lancet Respir Med 2013;1:210-223.

16. Sharafkhaneh A, Southard JG, Goldman M, Uryniak T, Martin UJ. Effect of budesonide/formoterol pMDI on COPD exacerbations: a double-blind, randomized study. Respir Med 2012;106:257-268.

17. Vestbo J, Anderson JA, Brook RD, Calverley PM, Celli BR, Crim C, Martinez F, Yates J, Newby DE; SUMMIT Investigators. Fluticasone furoate and vilanterol and survival in chronic obstructive pulmonary disease with heightened cardiovascular risk (SUMMIT): a double-blind randomised controlled trial. Lancet $2016 ; 387: 1817-1826$.

18. Wedzicha JA, Banerji D, Chapman KR, Vestbo J, Roche N, Ayers RT, Thach C, Fogel R, Patalano F, Vogelmeier CF; FLAME Investigators. Indacaterolglycopyrronium versus salmeterol-fluticasone for COPD. N Engl J Med $2016 ; 374: 2222-2234$.

19. Chrystyn H, van der Palen J, Sharma R, Barnes N, Delafont B, Mahajan A, Thomas M. Device errors in asthma and COPD: systematic literature review and meta-analysis. NPJ Prim Care Respir Med 2017 (in press).

20. Horsley MG, Bailie GR. Risk factors for inadequate use of pressurized aerosol inhalers. J Clin Pharm Ther 1998;13:139-143. 
21. De Blaquiere $P$, Christensen DB, Carter WB, Martin TR. Use and misuse of metered-dose inhalers by patients with chronic lung disease: a controlled, randomized trial of two instruction methods. Am Rev Respir Dis 1989;140:910916. 


\section{Figure Legends}

Figure 1. Mean change from baseline in trough FEV 1 over $(A) 24$ weeks (ITT population) and (B) 52 weeks (EXT population). The bars indicate $95 \%$ confidence intervals. $\mathrm{BUD}=$ budesonide; $\mathrm{Cl}=$ confidence interval; $\mathrm{EXT}=$ extension; $\mathrm{FEV}_{1}=$ forced expiratory volume in 1 second; FF = fluticasone furoate; FOR = formoterol; ITT = intent-to-treat; LS = least squares; UMEC = umeclidinium; VI = vilanterol.

Figure 2. Mean change from baseline in 4-weekly E-RS total score (ITT population). The bars indicate $95 \%$ confidence intervals. BUD = budesonide $; \mathrm{Cl}=$ confidence interval; E-RS = Evaluating Respiratory Symptoms; FF = fluticasone furoate; FOR = formoterol; ITT = intent-to-treat; LS = least squares; UMEC = umeclidinium; VI = vilanterol. 


\section{Tables and Figures}

Table 1. Patient Characteristics at Baseline (ITT and EXT Populations)*

\begin{tabular}{|c|c|c|c|}
\hline \multirow[b]{2}{*}{ Characteristic } & \multicolumn{3}{|c|}{ ITT Population (24 Weeks) } \\
\hline & $\begin{array}{c}\text { FF/UMEC/VI } \\
100 / 62.5 / 25 \mu g \\
(n=911)\end{array}$ & $\begin{array}{l}\text { BUD/FOR } \\
400 / 12 \mu g \\
(n=899)\end{array}$ & $\begin{array}{c}\text { Total } \\
(\mathrm{N}=1,810)\end{array}$ \\
\hline Age, yr & $64.2(8.56)$ & $63.7(8.71)$ & $63.9(8.64)$ \\
\hline Female, n (\%) & $233(26)$ & $236(26)$ & $469(26)$ \\
\hline Current smokers, n (\%) & $400(44)$ & $394(44)$ & $794(44)$ \\
\hline Smoking pack-years & $39.5(21.87)$ & $39.2(22.15)$ & $39.4(22.00)$ \\
\hline Cardiovascular risk factors $^{\dagger}, \mathrm{n}(\%)$ & $599(66)$ & $602(67)$ & $1,201(66)$ \\
\hline \multicolumn{4}{|l|}{ Moderate/severe COPD } \\
\hline \multicolumn{4}{|l|}{ exacerbation in previous 12} \\
\hline \multicolumn{4}{|l|}{ months, n (\%) } \\
\hline 0 & $313(34)$ & $317(35)$ & $630(35)$ \\
\hline 1 & $252(28)$ & $253(28)$ & $505(28)$ \\
\hline$\geq 2$ & $346(38)$ & $329(37)$ & $675(37)$ \\
\hline History of pneumonia, n (\%) & $87(10)$ & $99(11)$ & $186(10)$ \\
\hline $\mathrm{FEV}_{1}$ absolute, $\mathrm{mL}$ & $1349(0.46)$ & $1339(0.48)$ & $1344(0.47)$ \\
\hline $\mathrm{FEV}_{1}$ predicted, $\%$ & $45.5(12.97)$ & $45.1(13.64)$ & $45.3(13.30)$ \\
\hline SGRQ Total score & $51.8(16.29)$ & $50.8(16.73)$ & - \\
\hline \multirow[t]{3}{*}{ E-RS: COPD } & $13.20(5.828)$ & $12.97(5.928)$ & - \\
\hline & \multicolumn{3}{|c|}{ EXT Population (52 Weeks) } \\
\hline & $\begin{array}{c}\text { FF/UMEC/VI } \\
100 / 62.5 / 25 \mu g\end{array}$ & $\begin{array}{l}\text { BUD/FOR } \\
\text { 400/12 } \mu g\end{array}$ & Total \\
\hline
\end{tabular}




\begin{tabular}{|c|c|c|c|}
\hline & $(n=210)$ & $(n=220)$ & $(N=430)$ \\
\hline Age, yr & $63.7(7.76)$ & $63.3(8.43)$ & $63.5(8.10)$ \\
\hline Female, n (\%) & $53(25)$ & $58(26)$ & $111(26)$ \\
\hline Current smokers, n (\%) & $95(45)$ & $97(44)$ & $192(45)$ \\
\hline Smoking pack-years & $39.8(19.92)$ & $39.6(23.12)$ & $39.7(21.59)$ \\
\hline Cardiovascular risk factors $^{\dagger}, \mathrm{n}(\%)$ & $144(69)$ & $152(69)$ & $296(69)$ \\
\hline \multicolumn{4}{|l|}{ Moderate/severe COPD } \\
\hline \multicolumn{4}{|l|}{ exacerbation in previous 12} \\
\hline \multicolumn{4}{|l|}{ months, n (\%) } \\
\hline 0 & $62(30)$ & $72(33)$ & $134(31)$ \\
\hline 1 & $77(37)$ & $79(36)$ & $156(36)$ \\
\hline$\geq 2$ & $71(34)$ & $69(31)$ & $140(33)$ \\
\hline History of pneumonia, n (\%) & $18(9)$ & $20(9)$ & $38(9)$ \\
\hline $\mathrm{FEV}_{1}$ absolute, $\mathrm{mL}$ & $1425(0.50)$ & $1368(0.51)$ & $1396(0.51)$ \\
\hline FEV 1 predicted, $\%$ & $47.1(13.30)$ & $45.4(14.85)$ & $46.2(14.13)$ \\
\hline SGRQ Total score & $53.0(16.14)$ & $50.8(15.49)$ & - \\
\hline E-RS: COPD & $13.54(5.439)$ & $13.00(5.576)$ & - \\
\hline
\end{tabular}

Definition of abbreviations: BUD = budesonide; COPD = chronic obstructive pulmonary disease; E-RS: COPD = Evaluating Respiratory Symptoms in COPD;

$\mathrm{EXT}=$ extension; $\mathrm{FEV}_{1}=$ forced expiratory volume in 1 second; $\mathrm{FF}=$ fluticasone furoate; FOR = formoterol; ITT = intent-to-treat; $\mathrm{SD}$ = standard deviation; $\mathrm{SGRQ}=\mathrm{St}$ George's Respiratory Questionnaire; UMEC = umeclidinium; VI = vilanterol. *Data are mean (SD) unless otherwise stated.

${ }^{\dagger}$ Cardiovascular risk factors included, but were not limited to, hypertension, hypercholesterolemia, coronary heart disease, and diabetes mellitus. 
Table 2. Trough FEV 1 and SGRQ Responses (ITT and EXT Populations)

\section{ITT Population (24 Weeks)}

$\begin{array}{cc}\text { FF/UMEC/VI } & \text { BUD/FOR } \\ 100 / 62.5 / 25 \mu g & 400 / 12 \mu g \\ (n=911) & (n=899)\end{array}$

Trough $\mathrm{FEV}_{\mathbf{1}}, \mathrm{mL}$

LS mean at Week 24

1,418

1,247

$95 \% \mathrm{Cl}$

$1,401,1,434$

$1,230,1,263$

LS mean change from

baseline

142

$-29$

$95 \% \mathrm{Cl}$

126,158

$-46,-13$

FF/UMEC/VI vS. BUD/FOR

difference $(95 \% \mathrm{Cl})$

$171(148,194)$

P-value

$<0.001$

Proportion of trough $\mathrm{FEV}_{\mathbf{1}}$

responders*, $\mathbf{n}$

907

892

Responders, \% (n)

50 (453)

$21(184)$

FF/UMEC/VI vS. BUD/FOR

OR $(95 \% \mathrm{Cl})$

$4.03(3.27,4.97)$

$P$-value

$<0.001$

Change from baseline in

SGRQ Total score, n

846

791 
LS mean at Week 24

$95 \% \mathrm{Cl}$

LS mean change

$95 \% \mathrm{Cl}$

FF/UMEC/VI vs. BUD/FOR

difference $(95 \% \mathrm{Cl})$

$P$-value

Proportion of responders ${ }^{\dagger}$,

n

Responders, n (\%)

FF/UMEC/VI vs. BUD/FOR

OR (95\% Cl)

$P$-value
44.7

46.9

$43.8,45.5$

$-6.6$

$-7.4,-5.7$

$46.0,47.8$

$-4.3$

$-5.2,-3.4$

$$
\begin{gathered}
-2.2(-3.5,-1.0) \\
<0.001
\end{gathered}
$$

904

893

$448(50)$

$368(41)$

$1.41(1.16,1.70)$

$<0.001$

\section{EXT Population (52 Weeks)}

$\begin{array}{cc}\text { FF/UMEC/VI } & \text { BUD/FOR } \\ 100 / 62.5 / 25 \mu \mathrm{g} & 400 / 12 \mu \mathrm{g} \\ (\mathrm{n}=210) & (\mathrm{n}=220)\end{array}$

Trough FEV $\mathrm{V}_{\mathbf{1}}, \mathrm{mL}$

LS mean at Week 52

1,429

1,250

$95 \% \mathrm{Cl}$

$1,395,1,462$

$1,216,1,284$

LS mean change from

baseline

$-53$ 
$95 \% \mathrm{Cl}$

92,159

$-87,-20$

FF/UMEC/VI vs. BUD/FOR

difference $(95 \% \mathrm{CI})$

$179(131,226)$

$P$-value

$<0.001$

Proportion of trough $\mathrm{FEV}_{\mathbf{1}}$

responders* $^{*}, \mathbf{n}$

Responders, \% (n)

46 (96)

$16(34)$

FF/UMEC/VI vs. BUD/FOR

OR $(95 \% \mathrm{Cl})$

$4.79(3.02,7.61)$

$\boldsymbol{P}$-value

$<0.001$

Change from baseline in

SGRQ Total score, $n$

LS mean at Week 52

47.3

50.0

$95 \% \mathrm{Cl}$

$45.3,49.3$

$48.0,52.0$

LS mean change

$-4.6$

$-1.9$

$95 \% \mathrm{Cl}$

$-6.5,-2.6$

$-3.9,0.1$

FF/UMEC/VI vs. BUD/FOR

difference $(95 \% \mathrm{Cl})$

$-2.7(-5.5,0.2)$

$P$-value

0.065

Proportion of responders ${ }^{\dagger}$,

n

209

219

Responders, n (\%)

91 (44)

73 (33) 


\section{FF/UMEC/VI vs. BUD/FOR}

\section{OR $(95 \% \mathrm{CI})$}

\section{$P$-value}

$1.50(1.01,2.24)$

0.046

Definition of abbreviations: $\mathrm{BUD}=$ budesonide; $\mathrm{Cl}=$ confidence interval; $\mathrm{EXT}=$ extension; $\mathrm{FEV}_{1}=$ forced expiratory volume in 1 second; $F F$ = fluticasone furoate; FOR = formoterol; ITT = intent-to-treat; LS = least squares; OR = odds ratio; SGRQ = St George's Respiratory Questionnaire; UMEC = umeclidinium; VI = vilanterol . ${ }^{*}$ Response was defined as a trough $\mathrm{FEV}_{1}$ of $\geq 100 \mathrm{~mL}$ above baseline. ${ }^{\dagger}$ Response was defined as an SGRQ Total score change of $\geq 4$ units below baseline. 
Table 3. Annual Exacerbation Rates (ITT and EXT Populations)

\begin{tabular}{|c|c|c|c|c|}
\hline \multirow[b]{2}{*}{$\begin{array}{l}\text { Annual Rate of } \\
\text { COPD } \\
\text { Exacerbations }\end{array}$} & \multicolumn{2}{|c|}{ Up to 24 Weeks } & \multicolumn{2}{|c|}{ Up to 52 Weeks } \\
\hline & $\begin{array}{c}\text { FF/UMEC/VI } \\
100 / 62.5 / 25 \mu g \\
(n=911)\end{array}$ & $\begin{array}{l}\text { BUD/FOR } \\
400 / 12 \mu g \\
(n=899)\end{array}$ & $\begin{array}{c}\text { FF/UMEC/VI } \\
100 / 62.5 / 25 \mu g \\
(n=210)\end{array}$ & $\begin{array}{l}\text { BUD/FOR } \\
400 / 12 \mu g \\
(n=220)\end{array}$ \\
\hline Population, $\mathrm{n}$ & 907 & 892 & 210 & 219 \\
\hline \multicolumn{5}{|c|}{ Moderate and severe exacerbations } \\
\hline Mean rate & 0.22 & 0.34 & 0.20 & 0.36 \\
\hline $\begin{array}{l}\text { Ratio }(95 \% \mathrm{Cl}) \\
P \text {-value }\end{array}$ & \multicolumn{2}{|c|}{$0.65(0.49,0.86) ; 0.002$} & \multicolumn{2}{|c|}{$0.56(0.37,0.85) ; 0.006$} \\
\hline \multicolumn{5}{|l|}{ Reduction in } \\
\hline rate, $\%(95 \%$ & \multicolumn{2}{|c|}{$35(14,51)$} & \multicolumn{2}{|c|}{$44(15,63)$} \\
\hline $\mathrm{Cl})$ & & & & \\
\hline
\end{tabular}

Mild, moderate, and severe exacerbations
Mean rate
0.25
0.39
0.22
0.40
Ratio $(95 \% \mathrm{Cl})$;
$P$-value
Reduction in
rate, $\%(95 \%$
$35(16,50)$
$45(19,63)$
Cl)

Definition of abbreviations: $\mathrm{BUD}=$ budesonide; $\mathrm{Cl}=$ confidence interval; COPD = chronic obstructive pulmonary disease; EXT = extension; FF = fluticasone furoate; FOR = formoterol; ITT = intent-to-treat; UMEC = umeclidinium; VI = vilanterol. Ratios and $P$-values are calculated for FF/UMEC/VI vs. BUD/FOR. 
Table 4. Adverse Events and Adverse Events of Special Interest (ITT and EXT Populations)

ITT Population

(24 Weeks)

Adverse Events

Occurring in $\geq 2 \%$ of

Patients in Either

Population, n (\%)

Nasopharyngitis

Headache

URTI

COPD

Back pain

Arthralgia

Pneumonia

Pharyngitis

Oropharyngeal pain

Dizziness

Blood pressure

increased

$4(<1) \quad 8(<1)$

\section{EXT Population}

(52 Weeks)

\begin{tabular}{|c|c|c|c|}
\hline FF/UMFC/VI & BUD/FOR & FF/UMFC/VI & BUD/FOR \\
\hline $\begin{array}{c}100 / 62.5 / 25 \mu g \\
(n=911)\end{array}$ & $\begin{array}{l}400 / 12 \mu g \\
(n=899)\end{array}$ & $\begin{array}{c}100 / 62.5 / 25 \mu g \\
(n=210)\end{array}$ & $\begin{array}{l}400 / 12 \mu g \\
(n=220)\end{array}$ \\
\hline $64(7)$ & $43(5)$ & $23(11)$ & $22(10)$ \\
\hline $44(5)$ & $53(6)$ & $17(8)$ & $22(10)$ \\
\hline $20(2)$ & $19(2)$ & $6(3)$ & $10(5)$ \\
\hline $15(2)$ & $23(3)$ & $5(2)$ & $22(10)$ \\
\hline $19(2)$ & $18(2)$ & $4(2)$ & $5(2)$ \\
\hline $17(2)$ & $13(1)$ & $5(2)$ & $6(3)$ \\
\hline $19(2)$ & $7(<1)$ & $4(2)$ & $4(2)$ \\
\hline $15(2)$ & $9(1)$ & $5(2)$ & $1(<1)$ \\
\hline $9(<1)$ & $10(1)$ & $6(3)$ & $1(<1)$ \\
\hline- & - & $1(<1)$ & $6(3)$ \\
\hline
\end{tabular}

Dyspnea



$-$

0

$4(2)$

Vertigo

$-$

0

$4(2)$

Adverse Events of Special Interest

$\begin{array}{lcccc}\text { Cardiovascular effects } & 39(4.3) & 47(5.2) & 18(8.6) & 22(10.0) \\ \text { Pneumonia } & 20(2.2) & 7(0.8) & 4(1.9) & 4(1.8) \\ \text { Local steroid effects* }^{*} & 19(2.1) & 24(2.7) & 8(3.8) & 7(3.2)\end{array}$


Anticholinergic

syndrome*

$16(1.8) \quad 17(1.9) \quad 4(1.9) \quad 12(5.5)$

Hypersensitivity

$10(1.1)$

$10(1.1)$

$3(1.4)$

$1(0.5)$

Hyperglycemia/

diabetes**

$5(0.5)$

$4(0.4)$

0

$4(1.8)$

Decreased bone

$4(0.4)$

$6(0.7)$

$1(0.5)$

$1(0.5)$

mineral density

LRTI (excluding

pneumonia)

$3(0.3)$

$4(0.4)$

$1(0.5)$

0

Ocular effects*

$1(0.1)$

$4(0.4)$

Urinary retention

$1(0.1)$

0

Asthma/

0

$1(0.1)$

bronchospasm

Definition of abbreviations: BUD = budesonide; COPD = chronic obstructive pulmonary disease; EXT = extension; FF = fluticasone furoate; FOR = formoterol;

ITT = intent-to-treat; LRTI = lower respiratory tract infection; UMEC = umeclidinium; $\mathrm{URTI}=$ upper respiratory tract infection; $\mathrm{VI}=$ vilanterol. * These terms are derived from the Standardized Medical Dictionary for Regulatory Activities (MedDRA).

${ }^{* *}$ New-onset diabetes. 



Figure 1

$242 \times 333 \mathrm{~mm}(300 \times 300$ DPI $)$ 


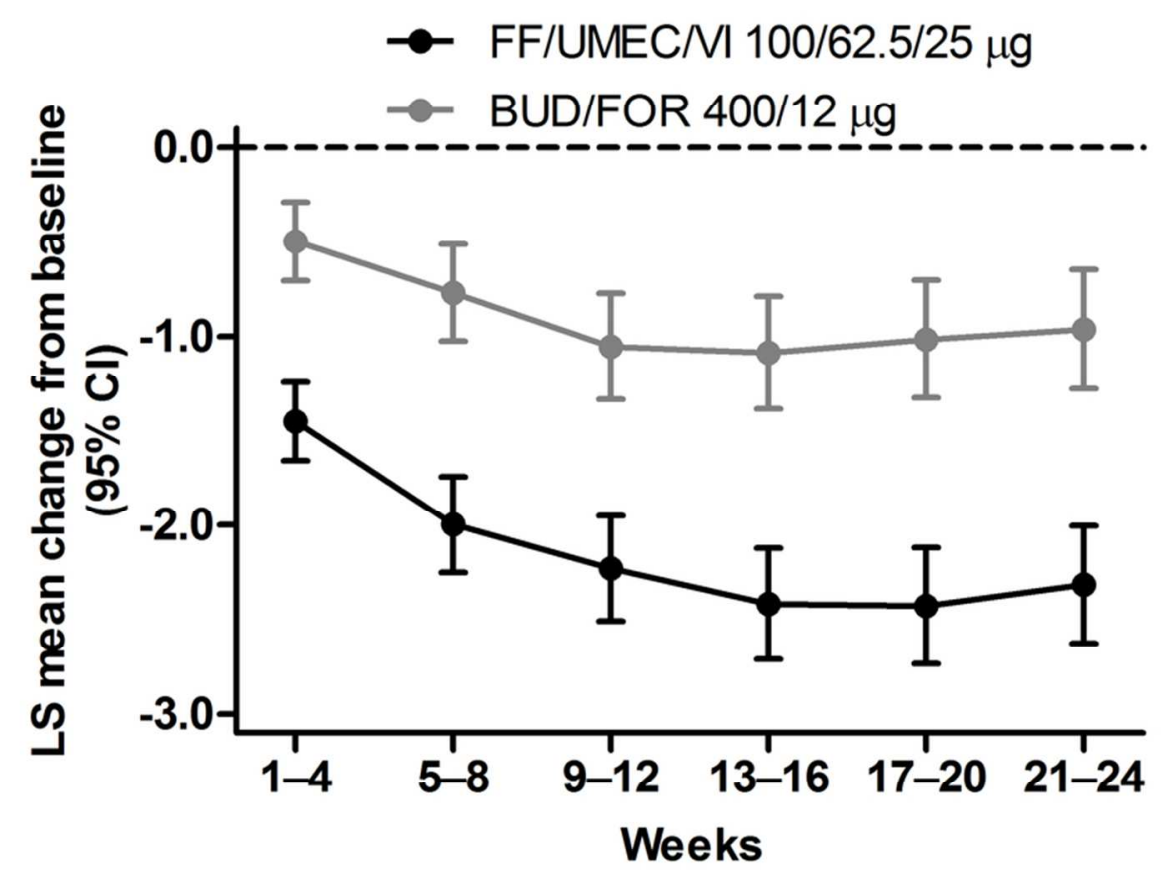

Figure 2

$79 \times 57 \mathrm{~mm}(300 \times 300$ DPI $)$ 


\section{FULFIL Trial: Once-Daily Triple Therapy in Patients with Chronic Obstructive Pulmonary Disease}

David A. Lipson, Helen Barnacle, Ruby Birk, Noushin Brealey, Nicholas Locantore,

David A. Lomas, Andrea Ludwig-Sengpiel, Rajat Mohindra, Maggie Tabberer, Chang-Qing Zhu, and Steven J. Pascoe

Online Data Supplement 


\section{Methods}

\section{Patients}

Patients were enrolled from approximately 200 study centers globally. Additional criteria for excluding patients from the FULFIL study were: chronic obstructive pulmonary disease (COPD) caused by $\alpha_{1}$-antitrypsin deficiency, other significant respiratory disorders, lung resection within 12 months of screening, or other clinically significant diseases. Patients who had pneumonia or severe COPD exacerbations were excluded if the events had not resolved within 14 days of screening. Patients with a respiratory tract infection that had not resolved within 7 days of screening, an abnormal chest X-ray, or an abnormal and clinically significant 12-lead electrocardiogram (ECG) finding were also excluded.

Patients were randomized using the interactive voice recognition system (Registration and Medication Ordering System [RAMOS]), stratified by smoking status.

\section{Efficacy Assessments}

COPD exacerbations were defined as: mild (self-managed by the patient by increasing rescue medication use); moderate (required treatment with oral/systemic corticosteroids and/or antibiotics, without hospitalization); or severe (required inpatient hospitalization).

Daily symptoms were recorded in electronic diaries (eDiaries). The eDiary alerted the patient to contact their investigator if they had worsening symptoms over three consecutive days, and the patients were instructed to contact their investigator if they received this alert. Investigators also received an alert. Data were automatically 
downloaded from the eDiary and transferred to a portal that could be accessed by the investigators. An interaction between the patient and the investigator was required to allow a physician to determine whether changes in symptoms were simply normal variation in the disease, or necessitated further therapy. Thus, the diagnosis of an exacerbation required clinical judgment combined with reported symptoms, mimicking clinical practice.

\section{Safety Assessments}

Patients recorded adverse events (AEs) and any medications using a diary worksheet and details were transcribed to the electronic case report form. ECG measurements, vital signs, and hematology and clinical chemistry parameters were recorded. COPD exacerbations were an expected disease-related outcome; thus, they were not recorded as an AE, unless they met the definition of a serious adverse event (SAE). All SAEs reported during the study were adjudicated by an independent clinical endpoint committee. Adverse events of special interest were defined a priori to evaluate potential AEs typically associated with the pharmacologic classes of inhaled corticosteroids, long-acting muscarinic antagonist, and long-acting $\beta_{2}$-agonist (Table E1).

\section{Statistical Analyses}

Based on the co-primary endpoints and previous experience with the drugs, sample size was calculated to be 688 patients per treatment group, which provided at least $90 \%$ power to detect a between-treatment difference of $80 \mathrm{~mL}$ for trough forced expiratory volume in 1 second, assuming a standard deviation (SD) of $240 \mathrm{~mL}$, and 2.5 units for St George's Respiratory Questionnaire Total score, assuming an SD of 
12 units, at 24 weeks at the $1 \%$ significance level. It was estimated that $30 \%$ of patients would discontinue treatment without being assessed at Week 24 and therefore 900 randomized patients were required for each treatment group.

Covariates used in the analysis of the co-primary endpoints included treatment group, smoking status, geographical region, visit, baseline value, and baseline-byvisit and treatment group-by-visit interactions.

Least squares (LS) means and LS mean change from baseline with standard errors and $95 \%$ confidence intervals were calculated. The number of on-treatment moderate/severe exacerbations and the number of mild/moderate/severe exacerbations were analyzed using a generalized linear model assuming a negative binomial distribution. Average scores for the Evaluating Respiratory Symptoms in COPD over 4-week intervals were analyzed using mixed model repeated measures. Secondary and other efficacy analyses were not adjusted for multiplicity.

\section{Results}

\section{Safety Analyses}

Drug-related AEs (assessed by the investigator) were reported by $5 \%$ of patients in the intent-to-treat population, with no single event occurring in more than $1 \%$ of patients in either group. Drug-related SAEs occurred in $<1 \%$ of patients and there were no drug-related deaths. 
Table E1. List of Evaluated Adverse Events of Special Interest

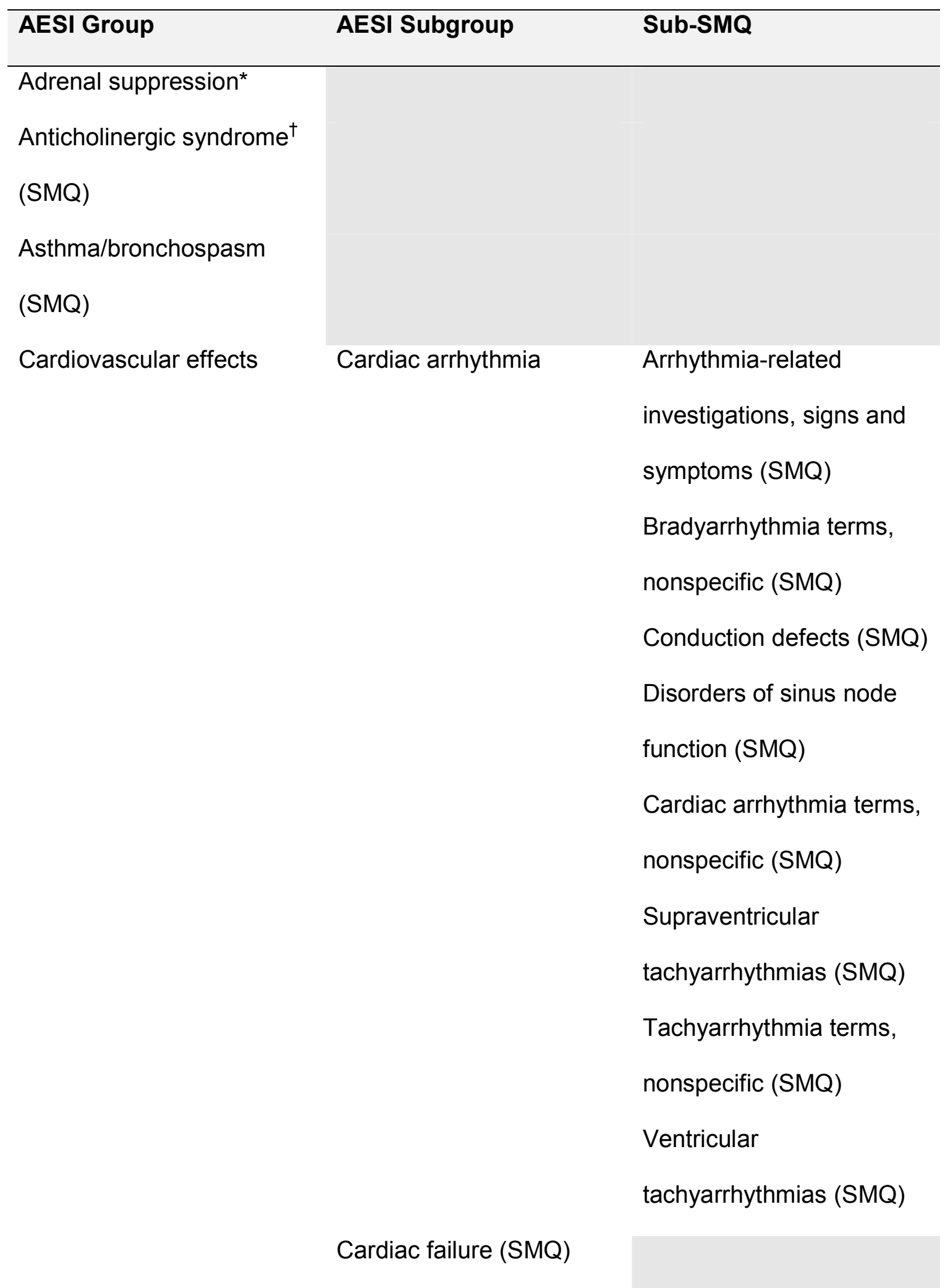




Ischemic heart disease
(SMQ)
Hypertension (SMQ)
Central nervous system
hemorrhages and
cerebrovascular
conditions (SMQ)
Glaucoma (SMQ)
Ocular effects ${ }^{\dagger} \quad$ Lens disorder (SMQ)

Decreased bone mineral

density and associated

fractures ${ }^{\ddagger}$

Effects on potassium*

Gastrointestinal obstruction

(SMQ)

Hyperglycemia/new onset

diabetes mellitus (SMQ)

Hypersensitivity*

Local steroid effects* ${ }^{\dagger}$

Pneumonia and LRTI

Pneumonia*

LRTI excluding

pneumonia*

Tremor*

Urinary retention* 
Definition of abbreviations: AESI = adverse events of special interest; LRTI = lower respiratory tract infection; SMQ $=$ Standardized Medical Dictionary for Regulatory Activities Query.

*Selected Medical Dictionary for Regulatory Activities Preferred Terms.

${ }^{\dagger}$ These terms are derived from the Standardized Medical Dictionary for Regulatory Activities (MedDRA). "Anticholinergic syndrome" is derived from the broad version of the Standardized MedDRA query (SMQ) called "Anticholinergic syndrome (SMQ)". This includes 50 preferred terms such as agitation, anhidrosis, ataxia, dry mouth, dry eye, and mydriasis. "Ocular effects" is derived from the broad version of "Glaucoma (SMQ)" (74 terms) and the "Lens disorders (SMQ)" (38 terms), including terms such as glaucoma, cataracts, eye pain, intraocular pressure increased, halo vision, vision blurred, and visual acuity reduced. "Local steroid effects" includes a list of 19 preferred terms such as oral candidiasis, mucocutaneous candidiasis, dry throat, and dysphonia.

${ }^{\ddagger}$ Osteoporosis/osteopenia SMQ plus selected Medical Dictionary for Regulatory Activities Preferred Terms. 
Table E2. COPD Medications Taken During Screening by $\geq 5$ Patients in Either Treatment Group

\begin{tabular}{|c|c|c|c|}
\hline \multirow[b]{2}{*}{$\begin{array}{l}\text { Medication Combination* } \\
\text { Full Medication Combination }{ }^{\dagger}\end{array}$} & \multicolumn{3}{|c|}{ Patients, n (\%) } \\
\hline & $\begin{array}{c}\text { FF/UMEC/VI } \\
100 / 62.5 / 25 \mu g \\
(n=911)\end{array}$ & $\begin{array}{l}\text { BUD/FOR } \\
400 / 12 \mu g \\
(n=899)\end{array}$ & $\begin{array}{c}\text { Total } \\
N=1,810\end{array}$ \\
\hline $\mathrm{ICS}+\mathrm{LABA}$ & $268(29)$ & $259(29)$ & $527(29)$ \\
\hline $\mathrm{ICS}+\mathrm{LABA}$ & $252(28)$ & $241(27)$ & $493(27)$ \\
\hline $\begin{array}{l}\text { ICS + LABA + short-acting } \\
\text { anticholinergic + short-acting } \beta_{2} \\
\text { agonist }\end{array}$ & $9(<1)$ & $6(<1)$ & $15(<1)$ \\
\hline $\begin{array}{l}\text { ICS + LABA short-acting } \\
\text { anticholinergic }\end{array}$ & $3(<1)$ & $5(<1)$ & $8(<1)$ \\
\hline ICS + LABA + LAMA & $257(28)$ & $256(28)$ & $513(28)$ \\
\hline$I C S+L A B A+L A M A$ & $220(24)$ & $221(25)$ & $441(24)$ \\
\hline $\begin{array}{l}\text { ICS + LABA + LAMA + short-acting } \\
\text { anticholinergic + short-acting } \beta_{2} \\
\text { agonist }\end{array}$ & $11(1)$ & $6(<1)$ & $17(<1)$ \\
\hline ICS + LABA + LAMA + oxygen & $5(<1)$ & $8(<1)$ & $13(<1)$ \\
\hline ICS + LABA + LAMA + mucolytics & $5(<1)$ & $6(<1)$ & $11(<1)$ \\
\hline LABA + LAMA & $101(11)$ & $84(9)$ & $185(10)$ \\
\hline LABA + LAMA & $89(10)$ & 77 (9) & $166(9)$ \\
\hline LAMA & $79(9)$ & $79(9)$ & $158(9)$ \\
\hline LAMA & $64(7)$ & $70(8)$ & $134(7)$ \\
\hline LAMA + short-acting anticholinergic & $8(<1)$ & $5(<1)$ & $13(<1)$ \\
\hline
\end{tabular}


+ short-acting $\beta_{2}$ agonist

\begin{tabular}{|c|c|c|c|}
\hline LABA & $37(4)$ & $42(5)$ & $79(4)$ \\
\hline LABA & $27(3)$ & $30(3)$ & $57(3)$ \\
\hline LABA + short-acting anticholinergic & $6(<1)$ & $6(<1)$ & $12(<1)$ \\
\hline ICS + LABA + LAMA + xanthine & $33(4)$ & $44(5)$ & $77(4)$ \\
\hline$I C S+L A B A+L A M A+$ xanthine & $18(2)$ & $31(3)$ & $49(3)$ \\
\hline ICS + LABA + xanthine & $19(2)$ & $18(2)$ & $37(2)$ \\
\hline ICS + LABA + xanthine & $13(1)$ & $16(2)$ & $29(2)$ \\
\hline ICS & $15(2)$ & $12(1)$ & $27(1)$ \\
\hline ICS & $14(2)$ & $11(1)$ & $25(1)$ \\
\hline LABA + LAMA + xanthine & $10(1)$ & $12(1)$ & $22(1)$ \\
\hline LABA + LAMA + xanthine & $9(<1)$ & $7(<1)$ & $16(<1)$ \\
\hline ICS + LAMA & $5(<1)$ & $11(1)$ & $16(<1)$ \\
\hline ICS + LAMA & $3(<1)$ & $11(1)$ & $14(<1)$ \\
\hline LAMA + xanthine & $6(<1)$ & $3(<1)$ & $9(<1)$ \\
\hline
\end{tabular}

Definition of abbreviations: BUD = budesonide; COPD = chronic obstructive pulmonary disease; FF = fluticasone furoate; FOR = formoterol; ICS = inhaled corticosteroid; LABA = long-acting $\beta_{2}$-agonist; LAMA = long-acting muscarinic antagonist; UMEC = umeclidinium; VI = vilanterol.

${ }^{*}$ COPD respiratory medication class (RMC) combination based on the individual RMC and any combination of the RMCs: ICS, LABA, LAMA, Xanthine, and PDE4 Inhibitors.

${ }^{\dagger}$ COPD RMC combination based on all RMCs. 
Figure E1. Patient flow in the FULFIL study. BUD = budesonide; FF = fluticasone

furoate; FOR = formoterol; ITT = intent-to-treat; UMEC = umeclidinium; VI =

vilanterol.

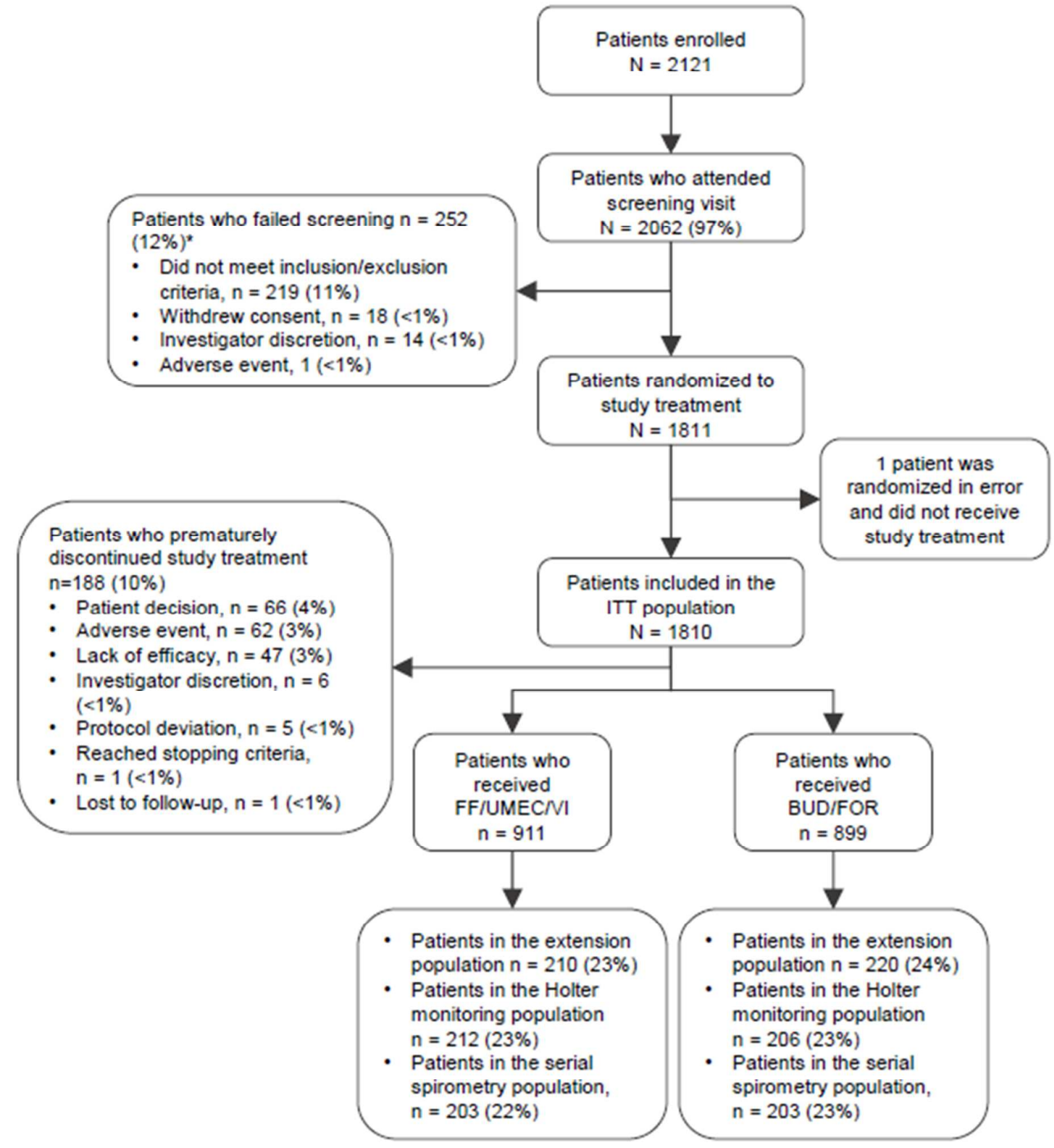

